\title{
Recycling Plastics to Crop Vegetables in Seawater
}

\author{
Manuel Jiménez Aguilar ${ }^{1}$
}

Received: 26 February 2015 / Accepted: 19 August 2015 / Published online: 7 September 2015

(C) Springer International Publishing Switzerland 2015

\begin{abstract}
The objective of the study was the design of a floating container for growing edible plants in the sea. The elements necessary for growing plants in the sea at low cost would be a solar still for producing freshwater, a pot or container plant breeding and a flotation system. To perform the functions of solar still and pot, different plastic bottles for packaging carbonated beverages, oil and water were used. With two bottles cut at their base and inserted into each other and a piece of iron polyurethane as floating system, it was possible to build a small solar greenhouse and use seawater to grow some man edible plants such as spinach (Spinacia oleracea L.) and wheat (Triticum aestivum L.). With a suitable design of the bottles (Mushroom-shaped), it would be possible to remove the floating system needed. The device can be used to recycle plastics and produce some green crops and food at low cost using seawater in an ecological and sustainable way.
\end{abstract}

Keywords Desalination $\cdot$ Seawater $\cdot$ Solar still $\cdot$ Vegetables $\cdot$ Greenhouse $\cdot$ Recycling plastic

\section{Introduction}

Worldwide Agriculture represents $70 \%$ of freshwater withdrawals from rivers, lakes and aquifers. The growing demand for agricultural products to meet the needs of a growing population remains the main factor affecting the consumption of water resources. The agricultural sector faces a complex challenge: producing more and better quality food using less water per unit of production. This freshwater consumption and expenditure needed would be nullified if we used seawater, the largest water resource on the planet. The elements necessary for growing plants in the sea at low cost would be a solar still for producing freshwater, a pot or container for plant breeding and a flotation system.

Manuel Jiménez Aguilar

manuel.jimenez.aguilar@juntadeandalucia.es

1 Instituto de Investigación y Formación Agraria y Pesquera, Consejería de Agricultura y Pesca, Junta de Andalucía, Camino de Purchil s/n, P.O. box 2027, 18080 Granada, Spain 


\subsection{Solar Still}

Different desalination technologies are being used to separate freshwater from saline water, including multi-stage flash, multiple effect, vapour compression, reverse osmosis, ion exchange, electro-dialysis, phase change and solvent extraction. These technologies are expensive to produce a small amount of freshwater. On the other hand, the use of conventional energy sources (hydrocarbons fuel) to drive these technologies has a negative impact on the environment. Solar distillation presents a promising alternative for saline water desalination that can partially support the humanity's needs for freshwater with free energy, simple technology and a clean environment. The development of solar distillation systems has demonstrated their suitability for the desalination process when the weather conditions are favourable and the demand is not too large, i.e., less than $200 \mathrm{~m}^{3} / \mathrm{d}$. The problem of low daily productivity of the solar stills triggered scientists to investigate various means of improving still productivity and thermal efficiency in order to reduce water production cost (Fath 1998).

The most simple and inexpensive process for freshwater is the evaporation of seawater using the sun's heat. Solar still is possibly the oldest method of desalination of water, used to produce distilled water from seawater via solar energy. Its principle of operation is the greenhouse effect; the radiation from the sun evaporates water inside a closed glass covered chamber at a temperature higher than the ambient. The saline water is fed on a black plate in the lower portion of the solar distiller. The heat of the sun causes the water to evaporate and water vapour condenses to form purely distilled droplets of water when it reaches the cool transparent leaning surface made of glass or plastic. The droplets slide down along the leaning surface and are collected through special channels located under the leaning surface.

It takes about $1 \mathrm{kWh}$ of energy to produce $1 \mathrm{~kg}$ of steam or equivalent amount of distilled water. If steam is produced using solar energy, expenditure on fuel can be minimized (Sen et al. 2013).

\subsection{Irrigation with Seawater}

The use of seawater for irrigation of land plants has been limited in coastal areas and always subject to the construction of desalination plants through the process of reverse osmosis to obtain freshwater from seawater. The use of these waters to produce plants makes the process very costly in energy terms.

Solar stills require large land areas since their productivity is as low as $2-3 \mathrm{~L} / \mathrm{m}^{2}$ day, and such large land areas are generally available only in arid regions.

The diurnal and seasonal fluctuations in solar still productivity are intrinsically linked to the fluctuating water requirements of the plants. They are both driven by the same and varying insolation.

The solar still can be built adjacent to the controlled environment agriculture (CEA) system greenhouse. This minimizes water transport cost and storage requirements may be very small, since the distillate may be fed directly into CEA system soil (Kudish and Gale 1986).

Constantz (1989) proposed a method for combining solar distillation and drip irrigation to simultaneously desalinize water and apply this water to row crops. A simple device was constructed primarily of sheets of plastic, which uses solar energy to distill impaired water and apply the distillate to a widely spaced row crop.

Seawater impact on the growth and yield of barley and on the characteristics of soil was investigated by Ghadiri et al. (2006). The results of both pot and field experiments showed that a 1:1 mixture of Caspian Sea and well water could be used for irrigation without a significant 
reduction in the growth and yield of barley, provided that it was not applied earlier than the time of ear formation. Soil analysis after harvest showed that the electrical conductivity had increased significantly in both diluted seawater treatments. This may suggest that the mixing of sea and ground waters at the rates used in these experiments may not be sustainable over a long period of time, and soil salinization may occur unless soils are of light texture and sufficient good quality freshwater or winter rain is available to lower the salinity of soil between successive crops.

Forward osmosis (FO) is a novel and emerging low energy technology for desalination. The application of this new concept (fertiliser drawn FDFO desalination) is described by Phuntsho et al. (2012) for the desalination of saline water for irrigation, using fertilizer as a draw agent. Most soluble fertilizers can generate osmotic potential much higher than the seawater. Initial estimation indicates that, $1 \mathrm{~kg}$ of fertilizer can extract water from seawater ranging from 11 to 29 L. FDFO desalination can make irrigation water available at comparatively lower energy than the current desalination technologies.

Deserts and coastal areas have begun using seawater for irrigation of halophytes as Salicornia and Sarcocornia that can be exploited by man in some quality function (Ventura and Sagi 2012).

An Integrated Solar Green House (ISGH) for water desalination, plantation and wastewater treatment has been constructed by El Awady et al. (2014) and field tested under actual meteorological conditions at Giza, Egypt. ISGH can be used successfully to provide a lowcost solution in arid areas, where the freshwater is very limited. In addition, it is a relevant method of cultivation that provides desalinated water, cooling environment and humidifying environment in an integrated system.

However, all these systems cannot be considered a feasible long-term solution as the salts from seawater are transferred to the ground.

\subsection{Floating Systems}

A floating device for solar energy conversion and water distillation has been constructed by Henderson (2013). A flower pot capable of floating on freshwater (lakes, ponds, etc.) was used for some terrestrial plants that can survive with their roots submerged (Jiang 2005), while in the open ocean it was used to grow algae and other species that are adapted to salinity, like Gracilaria. Gracilaria is one of the largest genera of the seaweeds with more than 150 species. Gracilaria edulis is more abundant and utilised for more than two decades for agar production (a vegetable gelatin of marine origin). Gracilaria edulis can be cultivated successfully for 8 months each year with maximum growth rates during November-December. Cultivation methods employ a long-line rope, net culture and single floating-rope techniques (Ganesan et al. 2011).

\subsection{Recycling Plastic}

Since the introduction of plastic materials in the 1950s, the global production of plastics has increased rapidly and will continue in the coming decades. In today's society, the plastics used are an environmental problem. Once used they can remain in the environment for many years before degradation. High concentration of floating plastic debris have been reported in remote areas of the ocean, increasing the concern about the accumulation of plastic litter on the ocean surface (Cózar et al. 2014). Much of the plastic containers are recovered in plants treating municipal solid waste and can be recycled. Many small-scale initiatives have emerged to 
retrieve the plastic containers and use them in various uses, among which are some designs of individual rafts and floats to learn to swim.

The design of a device that would serve to recycle all plastic containers used could lead to a saving of raw materials and other resources and energy sources. This would lead to a reduction of environmental pollution which would benefit the landscape and the environment.

In this paper, we propose greenhouse agriculture in the sea. The idea of developing a marine greenhouse has already been proposed by other authors (e.g., Greenbaum 1979; Tang and Sun 2005; Abahusayn 2013). This new agriculture method can be considered sustainable, since it would not need any external supply of water and other inputs (support-substrate and fertilizers) similar to a common greenhouse in crop land.

The objective of the study was actually to recycle plastic in making a floating container for growing edible plants at low cost in seawater.

\section{Material and Methods}

For the development of plants in the sea we have to make a system that besides providing freshwater should be able to sustain and protect the plant floating on the water surface. Based on these conditions, we have devised our bottle floating greenhouse, which is designed to grow edible plants, at their various stages of development, floating in the water, and more specifically, in seawater.

The planting unit described herein comprises two plastic bottles cut at their base and inserted into each other in either upright or inverted positions (Fig. 1). A plastic bottle, about $30 \mathrm{~cm}$ long, was cut at the base and inserted about $10 \mathrm{~cm}$ in another of the same size also baseless. The space between the two bottles allows airflow outward, promoting plant respiration. The upper bottle serves as a condenser of the evaporated water and was where the plants emerge. The available space on the neck of the bottle bottom allows hosting of the substrate and plants. The lower bottle was uncapped and the top bottle could be used with its lid or inverted. To facilitate fertilization and plant management was best to cut the neck of the bottle top about $8 \mathrm{~cm}$, so that the cover becomes retractable and adaptable to the gradual growth of the plant. As plant support material, any substrate used in greenhouses can be used (e.g., peat, perlite, plant debris, compost, being the nearest and cheapest in this case, washed sea sand, etc.). In this case, depending on the bottle size, 100 to $500 \mathrm{~g}$ of three mixtures were placed in the neck of the bottle: inert substrate, agricultural soil and agricultural soil with olive stones. Thereafter, seeds of spinach (Spinacia oleracea L.) and wheat (Triticum aestivum L.) were added and the whole was wetted with a solution of urine with water (1/10 in volume).

The lower bottle without the base was partially, about $20 \mathrm{~cm}$, submerged in water, to catch a given volume of seawater. The water was collected from Mediterranean sea (Motril port, Granada, Spain; $\mathrm{pH}=7.8 ; \mathrm{EC}=39 \mathrm{dS} \mathrm{m}^{-1}$ ). At the beginning and end of the experiment, the $\mathrm{pH}$ and $\mathrm{EC}$ of each soil were measured in 1:1 soil/water suspensions, using a $\mathrm{pH} /$ ion meter, and a conductivity meter, respectively (both Crison 2002 models).

Our first experiments began in late 2013 and were developed throughout 2014 to the present. Some spinach plants (Spinacia oleracea L.) were sown in spring (March 2014) and kept at room temperature (Fig. 2). In December, due to low temperature, spinach was replaced by wheat seeds (Triticum aestivum L.) (Figs. 3, 4, 5 and 6). The plants were kept outside at room temperature until Christmas Day. Due to the Christmas holidays, it was impossible to maintain the samples outside, at room temperature. So, they were introduced in a growth chamber $\left(25^{\circ} \mathrm{C}\right)$, where they continue to develop autonomously until March 2015. 
1- Bottle 1 baseless

2- Bottle 2 baseless

Plants: Colour green

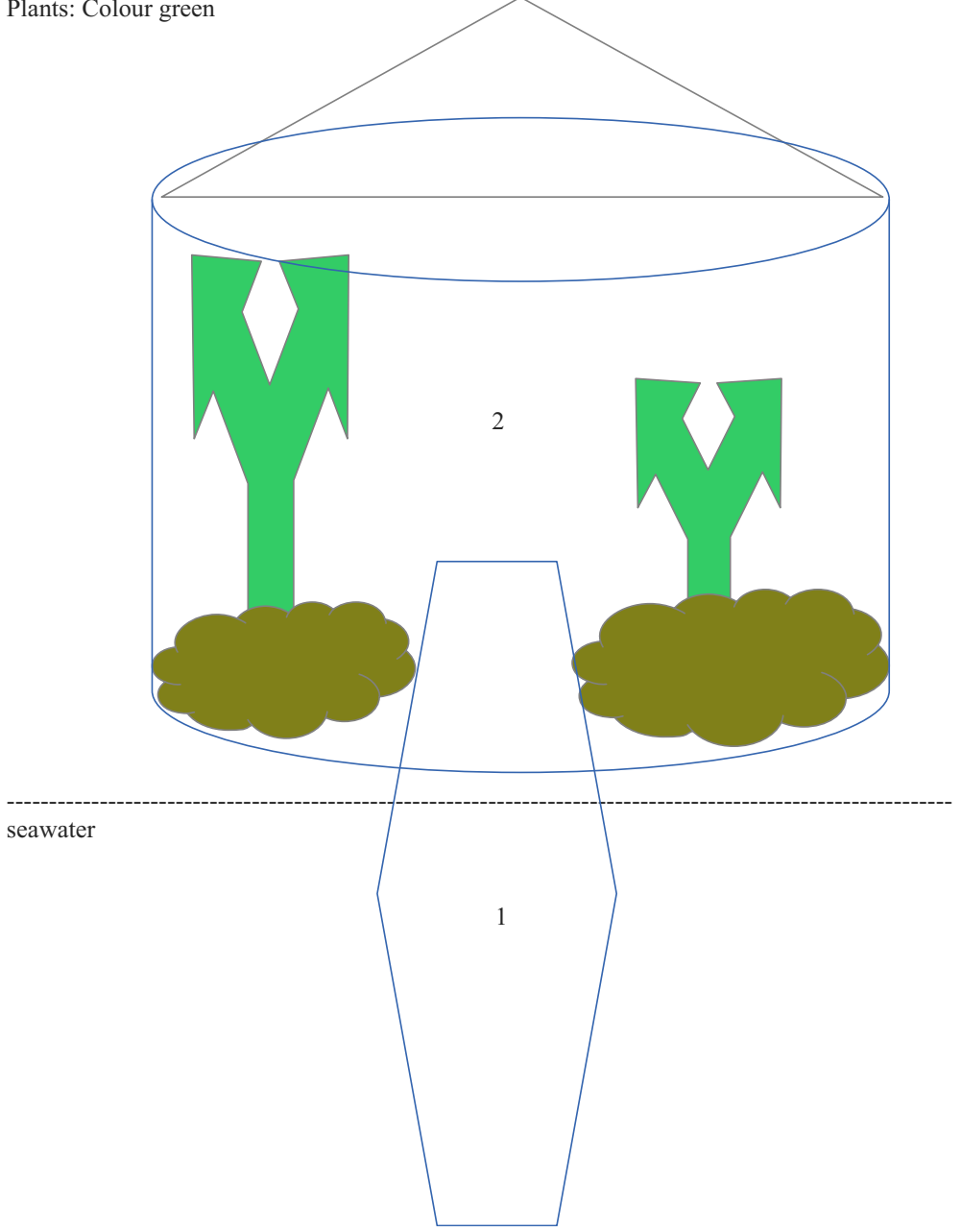

Fig. 1 Bottle-sea greenhouse

\section{Results and Discussion}

Our device can be considered a floating pot still. It works like a pot because plants can be grown, while it is a still because inside the bottle a part of the seawater condenses on the walls as freshwater and it floats on the surface of water (Ming 2003).

Water needs for a greenhouse tomato crop in Almería (Spain) range from 0.5 to $3.5 \mathrm{~L} \mathrm{~m}^{-2} \mathrm{~d}^{-1}$. In a conventional solar still, the production of freshwater in bright sunny weather and with warm air temperature is about 5-5.5 $\mathrm{L} \mathrm{m}^{-2} \mathrm{~d}^{-1}$, according to the depth of the water in the solar still. These results show that a solar still could meet the water needs of any greenhouse cultivation (Cappelletti 2002). Our device does not need addition of irrigation water. The evaporation of the marine water and the condensation of the freshwater on the walls of the bottle maintains the soil always moist. Inside the bottle, a kind of fractional distillation of the salt-water mixture takes 
Fig. 2 Spinach plants $(5 / 12 / 2014)$

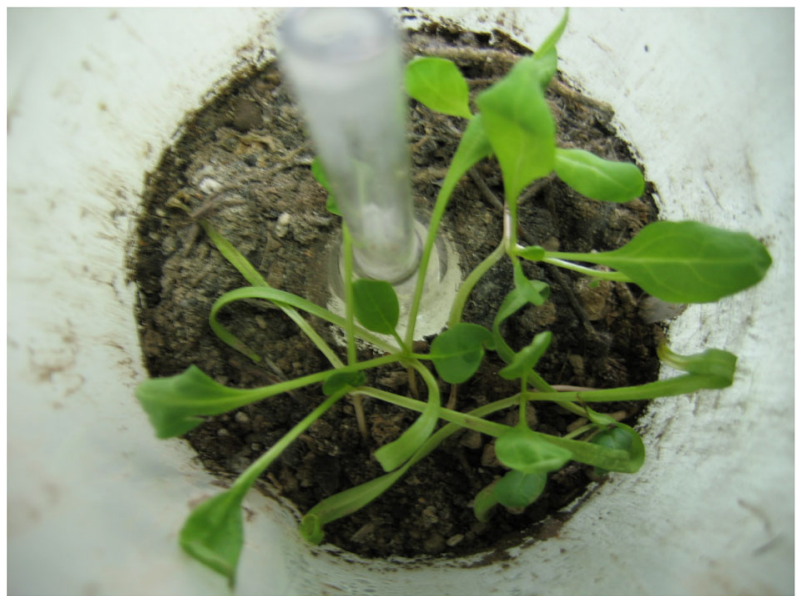

place, similar to a fractionating column of different phases or plates. Each of the ridges of the bottle at different heights can be considered a phase where salt is retained in its way up the walls. Also, the trapped air between the grooves of the bottles may be treated as a set of capillary tubes which when filled with water allows its ascent by capillarity. Throughout the experiment there was no increase in the salinity of the soil or substrate used which confirms that the bottles function as a solar still. The water drips down the walls of the bottle (about $0.25 \mathrm{~mL}$ per hour), which can be considered freshwater suitable for irrigation of any crop (Table 1).

With the closing and opening of the cap-lid, we can modify at will the evaporationcondensation of water, and thus, control the amount that reaches the ground in a similar manner to any irrigation system. The device does not need special care from the time of planting to harvest, so we can fully consider that it is ecological and self-sustaining. The retractable cover allows irrigation and fertilization management. A bottle designed with vertical grooves or spires could facilitate the dripping of condensed freshwater on the walls of the bottle.

Initially seed and fertilizer can join together in the substrate though the mobile cover which allows any later fertilization. The top of the bottle is used for protection against splashes of

Fig. 3 Algae and wheat roots in detail $(5 / 12 / 2014)$

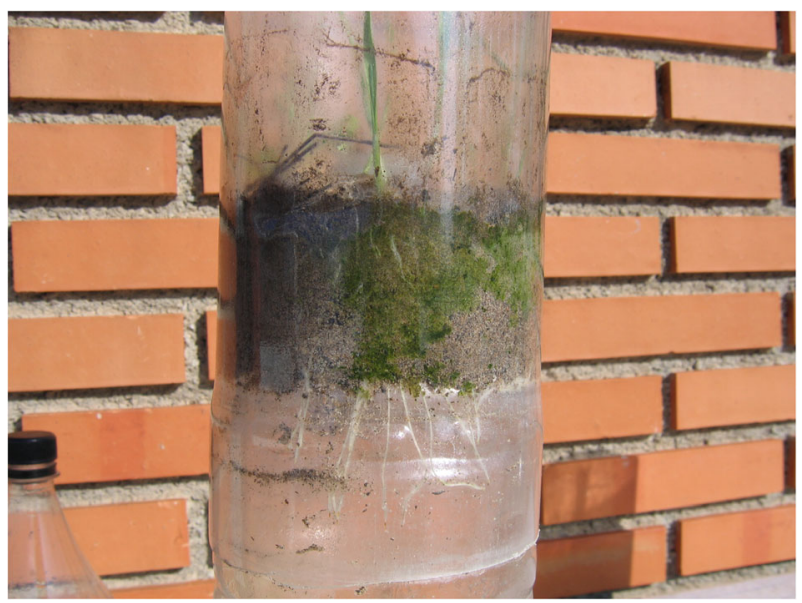


Fig. 4 Growing wheat plants with different bottles $(06 / 02 / 2015)$

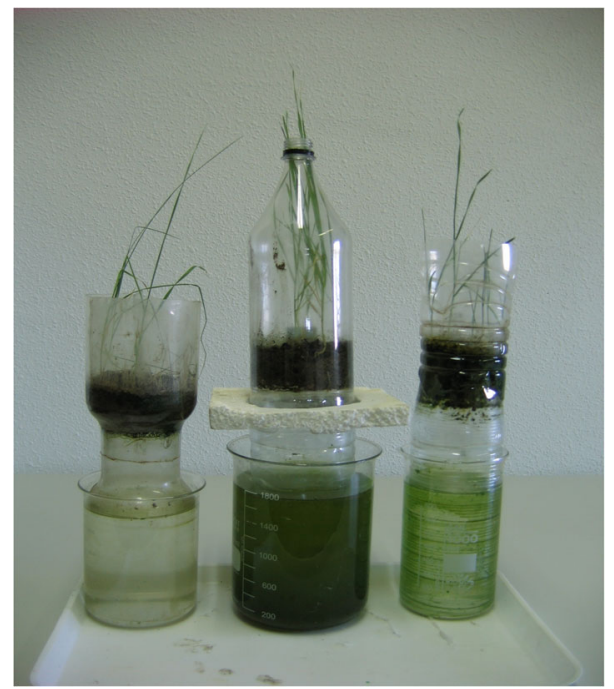

seawater caused by waves. The floating plate with the planting units must be attached to a ballast to prevent the drift of the system.

To grow freshwater plants, the piece of wall in contact with the substrate must be painted black to prevent algae growth. If you do not use this colour the system can produce algae and plants together (Fig. 3 shows a view of the roots and algae that grow on the side walls of some bottles). Depending on the size and characteristics of the plant, the bottles to be used could be

Fig. 5 Growing wheat plants with flotation system design (06/02/ 2015)

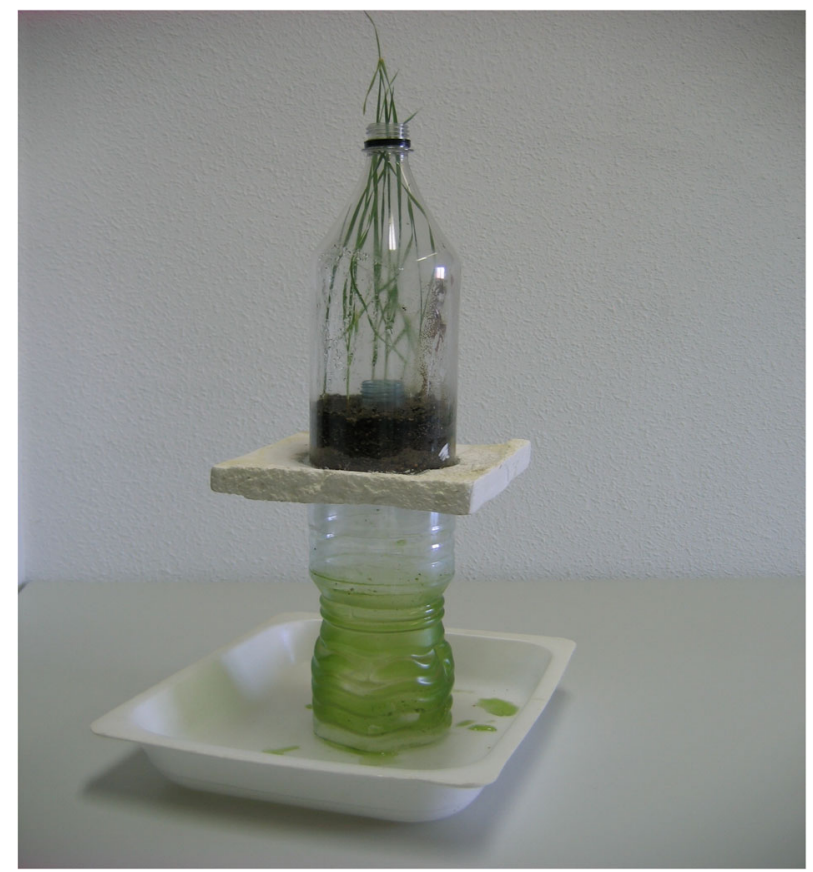


Fig. 6 Growing wheat plants without flotation system design $(20 / 02 / 2015)$

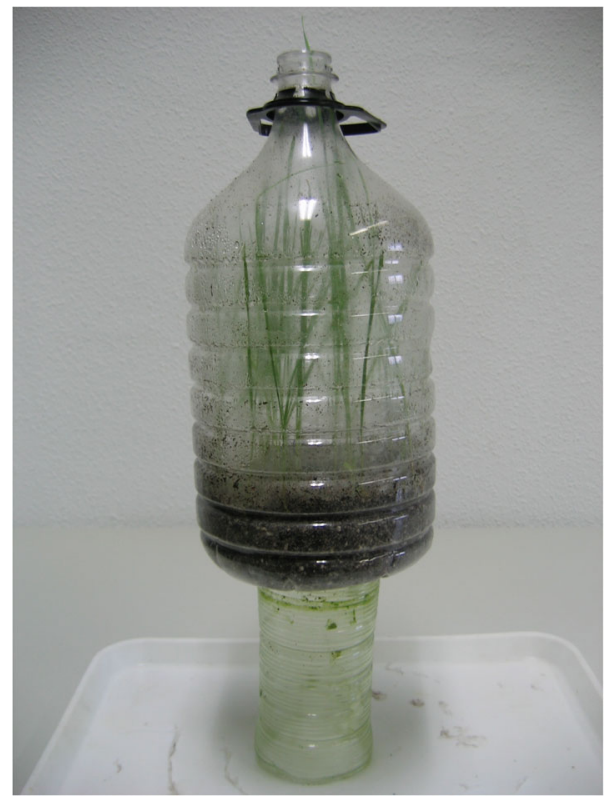

of different colour and sizes being preferred colourless or slightly blue (Fig. 4). Colourless bottles can be used as bioreactors for both seaweed farming and other halophytes.

A set of the two bottles was introduced into the hollow realised in a polyurethane foam sheet, about 15-20 cm below the polyurethane (see Fig. 5). The polyurethane can serve as the float, although for this purpose also methods indicated by different authors (e.g., Jiang 2005; Henderson 2013) may be used (see section 1.3).

If the diameter of the upper bottle is more than twice the lower, the volume of displaced water $\mathrm{V}=\left(3.14 \times 8^{2} \times 10\right) \mathrm{cm}^{3}$ exceeds the total weight of the system $(\mathrm{W}=500 \mathrm{~g})$ and the system would float without using any additional flotation system. So, a suitable design of the bottles (Mushroom-shaped), could replace any other floating system (see Fig. 6).

Provided that floating platforms already exist dedicated to marine fish farming, we can think of using these spaces and such systems of installation to form a marine ecosystem dedicated to both the production of marine fish and algae, and edible plants.

Unlike other authors, our design uses no different containers to hold water and to locate the substrate, fertilizer and plants. Also, the system does not need any power source (only the sun)

Table 1 Main effects of seawater on the $\mathrm{pH}$ and $\mathrm{EC}$ of soil and water

\begin{tabular}{lllllll}
\hline & \multicolumn{2}{l}{ Soil } & & & \multicolumn{2}{l}{ Water at walls } \\
\cline { 2 - 3 } \cline { 5 - 6 } & $\mathrm{pH}$ & $\mathrm{EC}\left(\mathrm{dS} \mathrm{m}^{-1}\right)$ & & $\mathrm{pH}$ & $\mathrm{EC}\left(\mathrm{dS} \mathrm{m}^{-1}\right)$ \\
\hline Substrate beginning & 7.3 & 1.30 & & & \\
Substrate end & 7.3 & 1.26 & & & \\
Soil beginning & 7.5 & 0.50 & & 7.7 & 0.047 \\
Soil end & 7.7 & 0.63 & & \\
Soil-olive stone begining & 7.5 & 0.60 & & 7.4 & 0.127 \\
Soil-olive stone end & 7.5 & 0.75 & & & \\
\hline
\end{tabular}


nor consumption of new materials (plastic bottles are recycled and disposable). Our device requires very little maintenance and energy consumption as the plant grows using the sun's energy and freshwater produced by evaporation of seawater.

The device can be considered a special apparatus for growing plants without soil; having a protective cover, promotes evaporation of water that serves as a self watering system for plant. It can be used for growing small plants in both freshwater lakes and in the sea. It is initially targeted to grow small plants intended for human or animal consumption although its use can be extrapolated to other fields. It can be used as: solar still to distill seawater and produce freshwater; to remove atmospheric $\mathrm{CO}_{2}$ through algae production; for growing plants to generate bio-fuels or to mitigate the effect of sea level rising due to global warming by trapping a portion of seawater and reducing evaporation into the atmosphere.

The system has some limitations for plants whose stem does not exceed $30 \mathrm{~cm}$, since their aerial part to emerge above the height of the bottle would be unprotected against salinity of ocean waves. In this case, these plants could only survive in protected areas like seaports or any other semi-enclosed marine space where the sea remains calm. In any case, the height and volume of the bottles must be adapted according to the plant growth, avoiding contact of the stem and leaves of the plant with the moisture on the walls of the bottle.

\section{Conclusions}

With two plastic bottles cut at their base and inserted into each other it is possible to build a small solar greenhouse and use seawater to grow some edible plants. With a suitable design of the bottles (Mushroom-shaped), it is also possible to avoid the use of a floating system needed for building the greenhouse at sea. The device can be used to recycle plastics and produce some green crops and food at low cost using seawater in an ecological and sustainable way.

Acknowledgements This study was funded by the Institute of Agricultural Research and Training, Andalusian Government. The author is grateful to the anonymous reviewers for insightful comments which greatly improved the quality of the manuscript.

Conflict of Interest The authors declare that they have no conflict of interest.

\section{References}

Abahusayn M (2013) Desalination greenhouse. Patent US 2013192131 (A1)

Cappelletti GM (2002) An experiment with a plastic solar still. Desal 142(3):221-227

Constantz J (1989) Distillation irrigation: a low-energy process for coupling water purification and drip irrigation. Agric Water Manag 15(3):253-260

Cózar A, Echevarría F, González-Gordillo JI, Irigoien X, Úbeda B, Hernández-León S, Palma T, Navarro S, Ruiz A, Fernández-de-Puelles ML, Duarte CM (2014) Plastic debris in the open ocean. Proc Natl Acad Sci U S A 111(28):10239-10244

El Awady MH, El-Ghetany HH, Latif MA (2014) Experimental investigation of an integrated solar green house for water desalination, plantation and wastewater treatment in remote arid Egyptian communities. Energy Procedia 50:520-527

Fath HES (1998) Solar distillation: a promising alternative for water provision with free energy, simple technology and a clean environment. Desalination 116(1):45-56

Ganesan M, Sahu N, Eswaran K (2011) Raft culture of Gracilaria edulis in open sea along the south-easten coast of India. Aquaculture 321(1-2):145-151 
Ghadiri H, Dordipour I, Bybordi M, Malakouti MJ (2006) Potential use of Caspian Sea water for supplementary irrigation in Northern Iran. Agric Water Manag 79(3):209-222

Greenbaum G (1979) Channel culture array using saline water. Patent US 4178715 A

Henderson RL (2013) Floating solar energy conversion and water distillation apparatus. Patent US 8465628 B1

Jiang S (2005) Floating flowerpot. Patent CN 2698059 Y

Kudish AI, Gale J (1986) Solar desalination in conjunction with controlled environmental agriculture in arid zones. Energy Convers Manag 26(2):201-207

Ming HS (2003) Floatable planting apparatus. Patent US 2003070357 A1

Phuntsho S, Shon HK, Hong S, Lee S, Vigneswaran S, Kandasamy J (2012) Fertiliser drawn forward osmosis desalination: the concept, performance and limitations for fertigation. Rev Environ Sci Biotechnol 11(2): 147-168

Sen PV, Bhuwanesh K, Ashutosh K, Engineer Z, Hegde S, Sen PK, Lal R (2013) Micro-scale multi-effect distillation system for low steam inputs. $5^{\text {Th }}$ BSME International Conference on Thermal Engineering. Procedia Eng 56:63-67

Tang CH S and Sun WH (2005) Floating plant cultivation platform and method for growing terrestrial plants in saline water of various salinities for multiple purposes. Patent US 2005044788 A1

Ventura Y, Sagi M (2012) Halophyte crop cultivation: The case for Salicornia and Sarcocornia. Environ Exp Bot 92:144-153 